\title{
A paradigm for experimental control of mediating verbal process
}

\author{
Kenneth W. Haun \\ DOUGLASS COLLEGE, RUTGERS UNIVERSITY
}

\begin{abstract}
Subjects learned A-B-C-D chains of meaningful words and were tested under positive, negative and neutral transfer conditions for A-C or A-D pairs. Transfer conditions were not mixed, but were uniform in each of three groups. Positive and negative transfer were demonstrated. It is asserted that this paradigm makes experimental control of mediating process possible. Problem
\end{abstract}

Mediating processes occupy a crucial position in many present psychological theories, especially those concerned with verbal behavior. The common approach to testing the effectiveness of these processes has involved tests of paired associates learning, with the evaluation of effect based on estimates of association strength, item overlap, and so on, derived from population values. These values are assumed to reflect internal hierarchies in the individual subject (Russel \& Lowell, 1955). Less commonly, there have been attempts to show mediation as a dynamic process by "building in" the mediators through learning (Peters, 1935; Foley \& Cofer, 1943; Bugelski \& Scharlock, 1952; Uehling, 1958; Norcross \& Spiker, 1955; Cofer, 1961). The evidence for mediation shown in these studies does not appear to be compelling. Indeed, if mediation is to have the important role assigned it theoretically, one might expect it to be a stronger effect.

On the other hand, the weakness of the obtained effects may depend either upon the measures employed, the estimates of strength of association used in designing and interpreting the studies, or the particular learning paradigm employed.

Another difficulty with the study of mediating process has been the problem of studying the relation of the mediating item to the task performance or to individual variables.

The present paper describes an attempt to avoid all these difficulties and presents a paradigm which allows experimental manipulation of the mediators.

\section{Method}

The Ss for this study were 60 Douglass College undergraduate females. Ss were randomly assigned to one of three groups of 20 each. These were designated as mediation, interference and control according to the experimental conditions. Each group then learned a series of paired associate lists consisting of 15 pairs of meaningful words each. The initial four lists were identical for all groups. The lists were so arranged that the responses for a prior list became the stimuli for the next list. Thus each subject learned a series of association chains consisting of four items each: $\mathrm{A} \longrightarrow$ $\mathrm{B} \longrightarrow \mathrm{C} \longrightarrow \mathrm{D}$. On the basis of free association norms obtained from the population from which the Ss were drawn, there were no known associations preexisting for any pair or for any item in the chain in either direction. Criterion for learning any particular list was two accurate repetitions of the list in a row. Stimuli and responses were presented on cards, with both stimulus and stimulus-response interval at $2 \mathrm{sec}$.

For the test condition, three lists of paired associates were constructed. In each group the stimuli were the same and were the same as those used as stimuli on the first list of the initial learning. In the case of mediation lists, the responses were selected from either the $\mathrm{C}$ or $D$ responses in a random manner but from the same chain as that originally initiated by the stimulus word. For the interference group a similar selection was made from either the $\mathrm{C}$ or $\mathrm{D}$ list but always from a different chain than the learned one (once again, zero association with the stimulus word was a condition). Finally, the control responses were words that had not previously appeared in any list.

It was predicted that the mediation group would show the most positive transfer, the control group the next, and the interference group, the least.

\section{Results}

Mean trials to learn for all groups and conditions are reported in Table 1. A groups by lists analysis of variance of these data showed significant differences in trials to learn from list to list $(\mathrm{F}=39.505 ; \mathrm{p}<.001)$ and a significant groups by list interaction $(\mathrm{F}=2.629$; $p<.025)$. Examination of the trends of the means shows that in all groups the number of trials to learn increased with each successive list until the test list, at which point there is a sharp drop in the mediation and control groups and the interference group remains essentially the same. Because of the apparent differences in trends for the various groups, $t$ tests were performed to determine if any group differed significantly from the others in initial learning. No pre-test group differences were significant, and it was concluded that the main source of the significant interaction variance was differences on the test trial. Analysis for mediation was thus based on differences between performance on List IV and the test list. The mean differences are indicated in Table 2. For a one-tailed test the critical difference in differences was $3.73(p<.05)$, thus the mediation group improved significantly more than the interference group but not more than the control; 
Table 1

Mean trials to learn a series of paired associate lists for three groups

\begin{tabular}{|c|c|c|c|c|c|c|}
\hline \multicolumn{6}{|c|}{ List } & \multirow{2}{*}{$\begin{array}{l}\text { Group } \\
\text { Means } \\
\end{array}$} \\
\hline Group & $\underline{\mathrm{LI}}$ & LII & LIII & $\underline{\text { LIV }}$ & Test & \\
\hline Mediation & 9.20 & 13.15 & 16.70 & 18.90 & 11.50 & 13.89 \\
\hline Control & 7.95 & 11.35 & 15.70 & 15.85 & 11.40 & 12.45 \\
\hline Interference & 7.50 & 13.05 & 13.45 & 15.10 & 14.30 & 12.68 \\
\hline List Mean & 8.22 & 12.52 & 15.28 & 16.62 & 12.40 & \\
\hline & & & & & Mean & 13.01 \\
\hline
\end{tabular}

and interference and control did not differ from each other.

\section{Diseussion}

The ranking of the groups in terms of improvement on the test trials was in the predicted direction, despite the fact that the control and interference groups did not significantly differ from each other. Given the rather unusual variation among group means on the pre-learning, even though not significant, it seems most plausible to assign the lack of precision to sampling error. Subsequent work with this paradigm has borne this out. When subjects are matched in terms of verbal intelligence, the course of pre-learning is identical for all groups.

The experiment conclusively shows mediation, both in the positive and negative sense. Since the pre-learning task was the same for all groups and since the stimuli and responses for the test list in both the mediation and interference groups were the same except for pairing, there is no other likely explanation for the difference in the groups.

It is possible, then, using this paradigm, to vary systematically the characteristics of the mediating item (the " $\mathrm{B}$ " item in the chain) or the characterisitcs of

Table 2. Mean differences between Trial IV and test trial

$\begin{array}{ccc}\text { Mediation } & \text { Control } & \text { Interference } \\ -7.40 & -3.45 & -.90\end{array}$

the groups, or the nature of the test condition, separately or together. Thus it should be possible to investigate mediation per se rather than as an inferred process.

An interesting possibility may be that the paradigm will yield useful information about process-process interactions as well. For example, if an $\mathrm{S}$ is taught $\mathrm{A} \longrightarrow \mathrm{B} \longrightarrow \mathrm{C} \longrightarrow \mathrm{D}$, then $\mathrm{E} \longrightarrow \mathrm{F} \longrightarrow \mathrm{G} \longrightarrow \mathrm{H}$ as a separate chain, what sort of effects are obtained if the final step is learning $\mathrm{B} \longrightarrow \mathrm{F}$, that is, an explicit association between mediators? Several of these possibilities have been studied by the present author and will be reported in subsequent papers.

\section{References}

BUGELSKI, B. R., \& SCHARLOCK, D. P. An experimental demonstration of unconscious mediated association. J. exp. Psychol., 1952, $44,334-338$.

COFER, C. N. (Ed.) Verbal learning and verbal behavior. New York: McGraw-Hill, 1961, 158-160, 213-214.

FOLEY, J. P., \& COFER, C. N. Mediated generalization and the interpretation of verbal behavior: II. Experimental study of certain homophone and synonym gradients. J. exp. Psychol., 1943, 32, 168-175.

NORCROSS, K. J., \& SPIKER, C. C. Effects of mediated associations on transfer in paired associate learning. J. exp. Psychol., 1958, 55, 129-134.

PETERS, H. N. Mediate association. J. exp. Psychol., 1935, 18, 20-48.

RUSSEL, W. A., \& LOWELL, H. S. Implicit verbal chaining in paired associate learning. J. exp. Psychol., 1955, 49, 287-293.

UEHLING, B. S. Frequency of association and similarity of meaning. Dissertation Abstracts. 1959, 19, 1828-1829. 